\title{
The role of inflammatory mediators in the development of prostatic hyperplasia and prostate cancer
}

This article was published in the following Dove Press journal:

Research and Reports in Urology

28 December 2012

Number of times this article has been viewed

Johny E Elkahwaji ${ }^{1-3}$

'Section of Urologic Surgery, ${ }^{2}$ Section of Medical Oncology and Hematology, ${ }^{3}$ Genitourinary Oncology Research Laboratory, University of Nebraska Medical Center, Omaha, NE, USA
Correspondence: Johny E Elkahwaji 987680 Nebraska Medical Center, Omaha, NE 68198-7680, USA

Tel +l 4025593903

Email jelkahwaji@unmc.edu
Abstract: Benign prostatic hyperplasia and prostate cancer remain the most prevalent urologic health concerns affecting elderly men in their lifetime. Only $20 \%$ of benign prostatic hyperplasia and prostate cancer cases coexist in the same zone of the prostate and require a long time for initiation and progression. While the pathogenesis of both diseases is not fully understood, benign prostatic hyperplasia and prostate cancer are thought to have a multifactorial etiology, their incidence and prevalence are indeed affected by age and hormones, and they are associated with chronic prostatic inflammation. At least $20 \%$ of all human malignancies arise in a tissue microenvironment dominated by chronic or recurrent inflammation. In prostate malignancy, chronic inflammation is an extremely common histopathologic finding; its origin remains a subject of debate and may in fact be multifactorial. Emerging insights suggest that prostate epithelium damage potentially inflicted by multiple environmental factors such as infectious agents, dietary carcinogens, and hormones triggers procarcinogenic inflammatory processes and promotes cell transformation and disease development. Also, the coincidence of chronic inflammation and tumorigenesis in the peripheral zone has recently been linked by studies identifying so-called proliferative inflammatory atrophy as a possible precursor of prostatic intraepithelial neoplasia and prostate cancer. This paper will discuss the available evidence suggesting that chronic inflammation may be involved in the development and progression of chronic prostatic disease, although a direct causal role for chronic inflammation or infection in prostatic carcinogenesis has yet to be established in humans. Further basic and clinical research in the area, trying to understand the etiology of prostatic inflammation and its signaling pathway may help to identify new therapeutic targets and novel preventive strategies for reducing the risk of developing benign and malignant tumors of the prostate.

Keywords: benign prostatic hyperplasia, prostate cancer, chronic inflammation, inflammatory mediators

\section{Background}

In spite of progress in diagnosis and treatment, benign prostatic hyperplasia (BPH) and prostate cancer $(\mathrm{CaP})$ remain the two main prostate pathologies and the two of the most prevalent urologic health concerns affecting men during their lifetime.

$\mathrm{BPH}$ is the most frequent benign neoplasm in aging males and one of the most common chronic conditions in the male population, with a histological prevalence at autopsy of $50 \%$ in men aged $50-60$ years and of $90 \%$ over 80 years old. ${ }^{2}$ As most chronic diseases, BPH is progressive. If untreated, it often complicates with bladder dysfunction and hypertrophy, possibly leading to acute urinary retention. ${ }^{3-5}$

$\mathrm{CaP}$ is currently the most common nonskin neoplasm and the second leading cause of death among men in the United States and many Western industrialized countries. ${ }^{6}$ 
$\mathrm{CaP}$ is predominantly a disease in men over 40 years of age and its incidence increases steeply in the seventh decade of life. In 2012, an estimated 241,740 men will be diagnosed with $\mathrm{CaP}$, and it is estimated that 28,170 deaths due to $\mathrm{CaP}$ will occur. ${ }^{6}$ Widespread screenings for prostate-specific antigen, digital rectal examination, and needle biopsy, as well as standard treatment already in clinical use, have enhanced patients' survival by improving detection of early and localized disease. However, there is still no cure for the advanced and metastatic disease.

Both $\mathrm{BPH}$ and $\mathrm{CaP}$ are considered chronic diseases with early initiation and slow progression. They require a period of time before they evolve from earlier tissue alterations to clinical onset. ${ }^{7}$ Both diseases arise in different areas of the prostate, with BPH known to develop in the transitional and the central zones and $\mathrm{CaP}$ in the peripheral zone. ${ }^{8}$ In only approximately $20 \%$ of clinical cases, both entities (BPH and $\mathrm{CaP}$ ) coexist in the same zone. ${ }^{8-10}$ Although the diseases are not thought to be linked in their etiology, epidemiologic studies have shown that the incidence and prevalence of both diseases rise with increased age, and both conditions are hormone dependent and are associated with prostatic inflammation. ${ }^{11,12}$

\section{The link between inflammation and carcinogenesis}

In the last decade, advanced cancer research has pointed out several cancer-causing factors including infection and inflammation. ${ }^{13-16}$ The role of infection/inflammation in the initiation and progression of cancer has been an area of intense scientific interest and is usually considered from the perspective that persistent inflammation in the context of chronic infection or tissue injury might promote cell transformation through DNA damage or that tumor cells produce proinflammatory factors that derive chronic inflammation and tumor growth. ${ }^{15,16}$ Several epidemiologic studies have shown that chronic inflammation secondary to infectious agents, to the exposure of other environmental factors, or to a combination of both is involved in the pathogenesis of about $20 \%$ of human cancers, including stomach (Helicobacter pylori), liver (Hepatitis B and C viruses), and colon cancer in patients with inflammatory bowel diseases. ${ }^{17,18}$ Furthermore, epidemiologic, histopathologic, and molecular pathologic studies suggest that chronic inflammation may be involved in the development and progression of chronic prostatic disease, such BPH and $\mathrm{CaP},{ }^{11-16}$ although a direct causal role for chronic inflammation or infection in prostatic carcinogenesis has yet to be confirmed and elucidated in humans.

\section{The definition of inflammation (acute and chronic)}

Inflammation is a fundamental physiological process that can arise in any tissue in response to traumatic, infectious, post-ischemic, toxic, or autoimmune injury. In the setting of tissue damage resulting from microbial pathogen infection or other noxious stimuli, these processes lead to eradication of pathogens, clearing of debris, epithelial regeneration, stromal remodeling, and vascularization to heal the wound and restore the normal tissue function. Once the repair is completed, the inflammatory reaction typically subsides. However, if targeted destruction and assisted repair are not properly phased, the immune system becomes deregulated and the infection persists. Inflammation becomes chronic due to persistence of the initiating factors (microbial pathogens or other noxious stimuli) and to a failure of mechanisms required for resolving the inflammatory response. Thus, the chronic inflammation promotes, whether directly or indirectly, an increase in cell proliferation, an enhancement of inflammatory cell recruitment, and excessive production of reactive oxygen and nitrogen species and active proteolytic enzymes, leading to oxidative DNA damage and reduced DNA repair. A microenvironment constituted by all the above inhabits the sustained cell proliferation induced by continued tissue damage, thus predisposing chronic inflammation to neoplasia and malignant transformation. ${ }^{19}$

\section{Prostatic inflammation}

Histologically, the presence of chronic prostatic inflammation is a well-known finding in biopsy and surgical specimens of prostate tissue in patients with or without lower urinary tract symptoms or prostatitis. ${ }^{20,21}$

\section{Prostatic inflammation, inflammatory immune cells, and BPH}

In clinical BPH patients, the most common type of inflammation found is a mild chronic inflammation. Its severity is associated with age and prostate volume in $78 \%$ of $\mathrm{BPH}$ cases, ${ }^{22-24}$ and defined by the presence of chronic inflammatory infiltrates composed of T- and B-lymphocytic cells and macrophages. ${ }^{16}$ Recently, a clinical study done in $282 \mathrm{BPH}$ patients confirmed the nature of the chronic inflammatory infiltrate, which was constituted by cluster of differentiation- $3^{+}\left(\mathrm{CD}^{+}\right)$T-lymphocytes in $80 \%$ of the cases and associated with $52 \%$ of B-lymphocytes (CD20 $0^{+}$ cells) and $82 \%$ of macrophages (CD163 cells). ${ }^{25}$ Finally, De Marzo et al described a discrete foci of proliferative glandular epithelium with an appearance of simple atrophy or postatrophic hyperplasia, which occurs in areas associated 
with chronic inflammation. The key features of this prostatic proliferative lesion are the presence of two distinct cell layers of mononuclear and/or polymorphonuclear inflammatory cells found in both epithelial and stromal compartments and stromal atrophy with a variable amount of fibrosis. ${ }^{26}$

\section{Prostatic inflammation and $\mathrm{CaP}$}

In CaP, chronic inflammation is increasingly discussed as a critical component of tumor carcinogenesis by generating a pathologically conducive microenvironment that may favor the initiation and progression of cancer. ${ }^{16}$ It is considered as a potential risk factor for many human malignancies including the prostate. Chronic inflammation induces cellular and genomic damage and promotes cellular turnover associated with a sustained inflammatory microenvironment that provides a constant supply of a variety of reactive nitrogen and oxygen species, reactive aldehydes, cytokines, chemokines, and growth factors, which can alter crucial biological processes responsible for maintaining normal cellular homeostasis, leading to uncontrolled proliferative response and genomic instability and risk of $\mathrm{CaP}$ development. ${ }^{27-29}$ Also, the high prevalence of chronic prostatic inflammation and the inflammatory infiltrates found in pathological samples of the prostate isolated from radical prostatectomy specimens, prostate core biopsy, and transurethral prostate specimens has suggested a possible link between chronic inflammation and $\mathrm{CaP}^{30,31}$ However, it is still unclear whether or not the same population of inflammatory infiltrates promotes both $\mathrm{BPH}$ and $\mathrm{CaP}$.

\section{The origin of prostatic inflammation}

The etiology of chronic prostatic inflammation remains a large subject of debate. Multiple potential sources exist and include direct infection, urine reflux or corpora amylacea, dietary factors, and hormones, or a combination of two or more of these factors. ${ }^{16}$

\section{Infectious agents}

Many epidemiologic studies have shown that different pathogens including bacteria and viruses could infect and induce an inflammatory response in the prostate. ${ }^{32}$ These pathogens include sexually transmitted organisms, such as Neisseria gonorrhoeae, Chlamydia trachomatis, Trichomonas vaginalis, and Treponema pallidum, and nonsexually transmitted bacteria primarily Gram-negative organisms, such as Escherichia coli, known to cause acute and chronic bacterial prostatitis. ${ }^{33-39}$ These organisms induce severe prostatic inflammation and prostatic abscesses if not treated with antibiotics on time, ie, before they reach the prostate. Also, many viruses such as human herpes simplex virus type-2, human papillomavirus, human cytomegalovirus, and human herpes virus type- 8 have been detected in the prostate, ${ }^{40-42}$ but it still is not clearly known how often these agents infect the prostate and whether or not they elicit an inflammatory response leading to inflammatory lesions in the prostate.

\section{Urine reflux, physical, and chemical trauma}

Another etiologic factor involved in the chronic prostatic inflammation is the chemical irritation caused by urine reflux. ${ }^{43}$ Urine contains many chemical compounds including uric acid that might be very toxic and particularly damaging to the prostate epithelium. ${ }^{44,45}$ In support of this, a recent work has implicated crystalline uric acid as a "danger signal" released from dying cells for its ability to directly engage the caspase-1-activating cryopyrin (NACHT, leucine-rich repeat, and pyrin domains-containing protein-3) present in the innate immune cells, primarily macrophages. The consequence of this process results in the production of many inflammatory cytokines that can increase the influx of many other inflammatory cells. ${ }^{45}$ Also, urine reflux in conjunction with infectious agents can function together to increase the severity and the intensity of chronic inflammation in the prostate. In addition, the development of corpora amylacea in the prostate is considered another resource of prostatic inflammation since they are frequently adjacent to the damaged prostatic epithelium and focal inflammatory infiltrates. ${ }^{46}$

\section{Dietary factors}

In addition, epidemiologic studies revealed a link between dietary factors and $\mathrm{CaP}$ incidence and mortality. ${ }^{47,48}$ Long-term exposure to dietary 2-amino-1-methyl-6phenylimidazo[4,5-b]pyridine results in prostate carcinomas in male rats, and could induce prostatic inflammation and atrophy before these lesions evolve into prostatic intraepithelial neoplasia (PIN) and cancers. ${ }^{48,49}$

\section{Hormones}

Moreover, hormonal alterations such as estrogen exposure affect the growth and development of the prostate through indirect routes on the hypothalamic-pituitary-gonadal axis or by direct effects mediated by estrogen receptor- $\alpha / \beta$, which are primarily expressed by stromal and epithelial cells, respectively. ${ }^{50-54}$ For example, estrogens given to neonatal rodents induce an "imprinted state," resulting in a reduction of prostatic growth. This treatment also results in the development of lobe-specific inflammation, hyperplasia, and dysplasia or PIN mediated virtually through estrogen receptor- $\alpha .{ }^{55,56}$ 


\section{Immune tolerance}

Finally, another potential mechanism of self-perpetuating chronic inflammation in the prostate secondary to all the above-mentioned modes of prostate injury is that damaged prostate epithelial cells might release some antigens that result in a break of the immune tolerance to the prostate. ${ }^{57}$ Many of these prostatic antigens are not expressed until after puberty when the gland will undergo androgen-stimulated growth and development. This phenomenon is likely to result in a lack of physiological immune tolerance to these antigens. Therefore, when released during the prostate injury, these antigens could prime an immune response resulting in a specific reaction to prostate-restricted antigens. For example, a T-cell immune response to prostate-specific antigen in patients with chronic prostatitis has been reported..$^{57}$

Taken together all the factors listed above, one or multiple factors in combination induce a chronic epithelial injury that may decrease the barrier function and facilitate the growth of multiple infectious agents, with a chain reaction that further sustains and stimulates the inflammatory response and increases the prostatic inflammatory infiltrates. Whether or not the chronic inflammation has a cause-and-effect relationship with $\mathrm{BPH}$ and $\mathrm{CaP}$ remains unknown.

\section{BPH and inflammatory mediators}

In BPH, chronic inflammation may cause cytokine release from the inflammatory cells and prostatic tissue injury induced by the increase of oxygen demand of prostatic proliferating cells. ${ }^{58,59}$ Also, cytokines, growth factors, and inflammatory mediators released by the inflammatory cells may interact not only with the immune effectors cells but also with the stromal and epithelial prostatic cells, resulting in a prostatic tissue injury. ${ }^{60}$ Multiple investigations done in this area have shown that lymphocyte-derived growth factors impact the prostatic stromal cell growth. ${ }^{61}$ These inflammatory infiltrates are chronically activated and responsible for the release of cytokines, mostly interleukin-2 (IL-2), interferon- $\gamma$, and tumor growth factor- $\beta$ (TGF- $\beta$ ), which may support the fibromuscular growth in BPH. ${ }^{58,59}$ Once initiated, dendritic cells induce, sustain, and regulate the infiltrates' T-cell responses and their activities contribute to the maintenance and progression of immune inflammatory infiltrates in the aging prostatic tissue. ${ }^{61,62}$

During chronic inflammation observed in BPH tissue, an upregulation of different proinflammatory cytokines has also been reported including IL-15 and interferon- $\gamma$ in stromal cells, IL-17 in infiltrating T-cells, and IL-8 in epithelial cells. ${ }^{58-61}$ These proinflammatory cytokines, more specifically IL-17, released by adjacent inflammatory cells induce cyclooxygenase-2 (COX-2) expression in the BPH epithelial cells and is associated with an increased proliferative rate (growth and survival of prostatic cells). ${ }^{63} \mathrm{IL}-17$ in conjunction with functional IL-23, a heterodimeric protein produced by activated dendritic cells, monocytes, and macrophages, and through the IL-17/IL-23 pathway promotes the inflammation response in the prostatic tissue. ${ }^{64-67}$

In BPH stromal cells, Penna et al recently showed that both interferon- $\gamma$ and IL-17, produced by the activated alloantigen-specific $\mathrm{CD} 4^{+} \mathrm{T}$-cells, induce the production of both IL-6 (a potent autocrine growth factor) and IL-8 (a paracrine inducer of fibroblast growth factor-2), which are the key growth factors of epithelial and stromal prostate cells. ${ }^{68}$ These results are consistent with a possible link between the T-cell autoimmune response induced by stromal prostatic cells and prostate hyperproliferation. ${ }^{68}$ Furthermore, it has been shown that TGF- $\beta$ regulates stromal cell proliferation and differentiation in $\mathrm{BPH}$ and it is a key factor for androgen control of prostatic growth. ${ }^{61,69}$

Another source of inflammatory mediators is the local hypoxia which induces low levels of reactive oxygen species, which in turn promotes neovascularization and angiogenesis. Also, as a response to hypoxia, prostatic stromal cells upregulate the secretion of multiple vascular endothelial growth factors such as fibroblast growth factor-2, fibroblast growth factor- 7 , TGF- $\beta$, and IL- 8 that can determine the prostatic growth rate..$^{58,67}$

Although there is still no evidence of a causal relationship between chronic inflammation and $\mathrm{BPH}$, the idea that prostatic inflammation may play an important role in BPH development and progression is intriguing. The inflammatory infiltrate-mediated T-cell activity results in stimulation of stromal and epithelial cell proliferation that is sustained by an autoimmune mechanism and the prostatic tissue injury. The subsequent chronic process of repetitive wound healing induced by chronic inflammation ends up by evolving the simple micronodular hyperplasia into a macroscopic nodular enlargement that gradually translates and progresses into the clinical entity of BPH nodules.

\section{The association between CaP and chronic prostatic inflammation}

In CaP, several key observations have supported the postulated relationship between chronic inflammation and prostate carcinogenesis. 


\section{Sexual transmitted diseases and CaP}

Epidemiologic studies have shown, perhaps due to inflammation-induced oncogenesis, that sexually transmitted diseases play a role in the initiation and progression of $\mathrm{CaP}^{70,71}$ An increased risk of $\mathrm{CaP}$ among patients with a history of clinical or symptomatic prostatitis has been reported. ${ }^{72-75} \mathrm{Also}$, several meta-analyses have demonstrated an increased risk of $\mathrm{CaP}$ among patients affected with syphilis, gonorrhea, and human papillomavirus infection. ${ }^{76,77}$ Finally, other indicators including number of sexual partners, age of first intercourse, sexual behavior, and frequency of sex have been reported with $\mathrm{CaP}$ risk. ${ }^{76-80}$

\section{Cytokine network and $\mathrm{CaP}$}

The cytokine network (Figure 1) including proinflammatory and anti-inflammatory cytokines is very useful not only for assessment of prostatic inflammation but also for early cancer detection and prognosis. ${ }^{81,82}$

\section{IL- I}

IL-1 is a proinflammatory cytokine that promotes the growth and progression of several solid tumors. ${ }^{83} \mathrm{IL}-1 \beta$ is required but not sufficient for metastasis of both B16 melanoma cells and human CaP cells in vivo, whereas IL-1 $\alpha$ is required for angiogenesis in a model of mammary carcinoma. ${ }^{83}$

\section{IL-6}

Another proinflammatory cytokine IL-6, involved in the crosstalk between $\mathrm{CaP}$ cells and inflammatory cells, promotes the malignant processes and induces apoptosis and angiogenesis. ${ }^{84-86}$ Also, it has been shown that IL-6 enhances cell proliferation and acts as a survival molecule for many prostate tumor cell lines such as PC3, LNCaP, and DU145. ${ }^{16,26}$ Clinically, elevated levels of IL-6 were found in the serum of patients with $\mathrm{CaP}$ metastatic disease, which was associated with poor disease prognosis. ${ }^{87}$

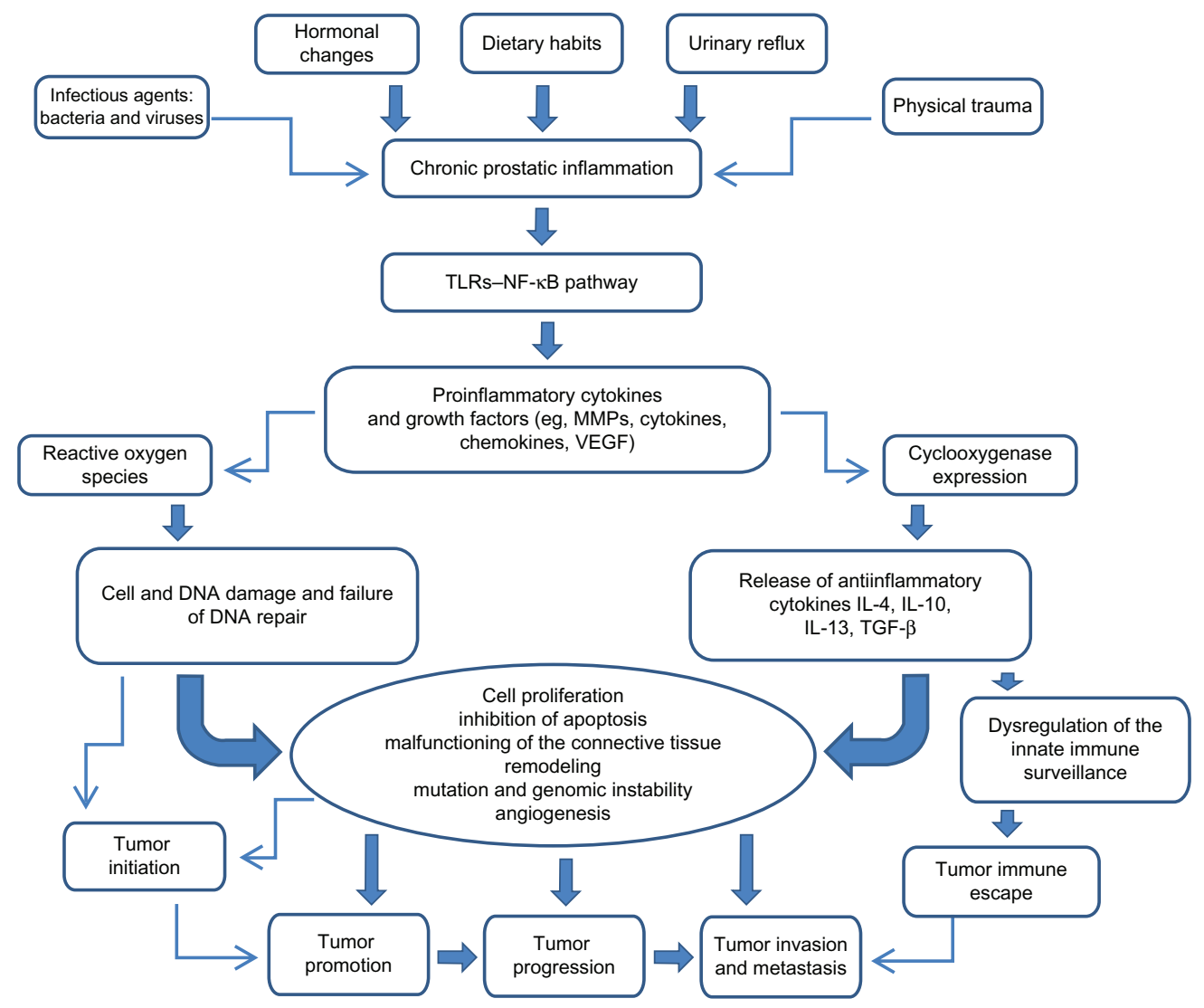

Figure I Impact of chronic prostatic inflammation and inflammatory mediators on tumor initiation and progression.

Notes: Chronic prostatic inflammation, inflicted by a variety of exposures, determine the activation of the TLR-NF- $\kappa B$ pathway on the inflammatory and prostatic tumor cells, and the release of proinflammatory mediators involved in cell transformation and disease development. Cytokines and growth factors induce the expression of cyclooxygenase and the production of reactive oxygen species. Overexpression of cyclooxygenase-2 deregulates the innate immune surveillance and induces the tumor immune escape leading to invasion and metastasis. Reactive oxygen species induce cell and DNA damage associated with mutations and genomic instability, leading to tumor initiation and promotion, tumor growth, tumor invasion, and metastasis.

Abbreviations: IL, interleukin; MMP, matrix metalloproteinase; NF- $\kappa B$, nuclear factor- $\kappa B$; TGF- $\beta$, transforming growth factor- $\beta$; TLR, toll-like receptor; VEGF, vascular endothelial growth factor. 


\section{IL-17}

IL-17, secreted by CD4 T-cells, promotes the migration of endothelial cells and induces fibroblasts to upregulate proangiogenic factors such as vascular endothelial growth factor, macrophage inflammatory protein-2, prostaglandins, and nitric oxide involved in angiogenesis and in vivo growth of tumor cells. ${ }^{88}$ Furthermore, Steiner et al have shown that $58 \%$ of human malignant prostate tissues have an increased level of IL-17 messenger ribonucleic acid and both prostate tumor cells and prostate stromal cells treated with IL-17 in vitro have an increase in messenger ribonucleic acid and protein expression of both IL-6 and IL-8. ${ }^{64}$ These data suggest that IL-17 acts directly on the prostate tumor cells and promotes their growth and metastasis, or indirectly by increasing the level of inflammatory cytokines and growth factors released locally in the prostate.

\section{IL-8}

Human IL-8, an inflammatory chemokine, promotes tumor cell growth and the progression of human solid tumors; this includes $\mathrm{CaP}$, due largely to its ability to regulate the expression of matrix metalloproteinases (MMPs) ${ }^{89}$ Numerous studies have demonstrated a correlation between MMPs, IL-8, and CaP. Increased levels of IL-8, MMP-2, and MMP-9 were associated with high Gleason scores and metastatic disease. Also, a high level of IL-8 leads to an increase in MMP-9 expression, which in turn may directly increase the tumor grade and metastasis in $\mathrm{CaP}$ patients. ${ }^{89,90}$

\section{TNF- $\alpha$}

TNF- $\alpha$, another pro-inflammatory cytokine, plays a role in many solid tumors' growth. Elevated serum levels of both TNF- $\alpha$ and IL- 6 have been shown to correlate with advanced metastatic disease and decreased survival in CaP patients. ${ }^{87}$ Additionally, TNF- $\alpha$ upregulates $\alpha v \beta 6$ expression, leading to increase in MMP-9 expression involved in extracellular matrix degradation, tumor progression, and metastasis in vitro and in vivo. ${ }^{91,92}$

\section{TGF- $\beta$}

TGF- $\beta$, a multifunctional cytokine, has been shown to increase the survival and proliferation of transformed prostate epithelial cells and is found at elevated levels in the serum of human CaP patients with metastatic disease. ${ }^{93,94}$ Loss of TGF- $\beta$ type I and II receptors on transformed human prostate epithelial cells correlates inversely with tumor grade and may allow escape from TGF- $\beta$-mediated growth regulation. Furthermore, TGF- $\beta$ activates the transcriptional factor nuclear factor- $\mathrm{\kappa B}$ and directly increases tumor cell survival. ${ }^{93-95}$

\section{Chemokines and CaP}

Chemokines are also involved in human prostate epithelial cells, growth and survival. It has been shown that these prostate epithelial cells produce a high level of macrophage chemotactic protein-1, which through the chemokine $(\mathrm{C}-\mathrm{C}$ motif) receptor-2 and the phosphatidylinositol 3-kinase modulates the proliferation and invasiveness of prostate tumor cells in vitro and in vivo and promotes metastasis in the prostate. ${ }^{96}$ Other studies have shown that chemokine ( $\mathrm{C}-\mathrm{C}$ motif) ligand-5 and its receptor chemokine ( $\mathrm{C}-\mathrm{C}$ motif) receptor-5 expressed on $\mathrm{CaP}$ cell surfaces may function as an autocrine factor and activate many cellular responses involved in cancer initiation, invasion, and progression. ${ }^{97,98}$

\section{Polymorphisms of proinflammatory genes and $\mathrm{CaP}$}

Polymorphisms of several cytokines genes such as TNF- $\beta 1$, IL-1 $\alpha / \beta$, IL-8, IL-10, and chemokine (C-C motif) receptor-5 can influence not only the inflammation and the immune response but are also mostly associated with susceptibility to $\mathrm{CaP}$, as observed in a large number of case-control studies, twin studies, and segregation analysis. ${ }^{66}$ It is widely hypothesized that the interactions of cytokine network genes, additively or epistatically, determine the individual risk for $\mathrm{CaP}$ as well as for $\mathrm{BPH}$, which is also described as an immune-mediated inflammatory disease.

\section{COX-2 and $\mathrm{CaP}$}

There is emerging evidence on the key role of COX-2 in prostate carcinogenesis. ${ }^{99} \mathrm{COX}-2$ is considered a promoter of proliferation in $\mathrm{CaP}$ and its expression is associated with reactive oxygen species production and genomic damage induced by chronic inflammation. ${ }^{28}$ Its rapid induction results in enhanced synthesis of prostanoids at the tumor site with several procarcinogenic effects including direct stimulation of prostate tumor growth and inhibition of immune surveillance in the prostate. Several reports have shown that $C O X-2$, an early-response gene induced by a variety of cytokines and growth factors, is involved in invasion and angiogenesis in vitro and in vivo and is upregulated in many human malignancies including CaP. ${ }^{28,67,98}$ This upregulation is seen throughout the tumorigenic process from early hyperplasia to metastatic disease, ${ }^{100-102}$ and has been described in many clinical cases with evolution of proliferative inflammatory atrophy (PIA) and PIN. ${ }^{103}$ 


\section{Genetic and epigenetic instability and $\mathrm{CaP}$ risk}

The common genetic and epigenetic instabilities in $\mathrm{CaP}$ include a strong representation of genes that encode proteins with critical functions in the host in response to infection, inflammation, and oxidative stress; their mutation may reduce the possibility of preventing carcinogenesis. ${ }^{30}$ These genes include but are not limited to phosphatase and tensin analog protein (PTEN), macrophage scavenger receptor (MSR1), Ribonuclease L (RNASEL), and Toll-like receptor 4 (TLR4). Recognition of their ligands determines a cascade of events associated with the activation of IL-1 receptor followed by the activation of the master inflammatory transcriptional regulator factor nuclear factor- $\mathrm{kB}$ and proinflammatory genes. ${ }^{66}$

\section{$\mathrm{PIA}$ as a precursor of $\mathrm{CaP}$}

PIA, the proliferative glandular epithelium with the morphological appearance of simple atrophy, occurs in association with chronic inflammation and it is thought to be a possible precursor of $\mathrm{CaP}$. This lesion arises as a consequence of regenerative proliferation of the prostatic epithelial cell in response to inflammatory injury. It is considered as a precursor of high-grade PIN and $\mathrm{CaP}^{26,30}$ Furthermore, it is often observed in proximity to high-grade PIN, and the morphologic transitions between PIA and high-grade PIN occur within the same acini or prostatic duct with an expression change of an antioxidant enzyme involved in the detoxification of carcinogens and inflammatory oxidants in prostate cells. This enzyme, glutathione S-transferase P1, is considered a signal of cellular stress and it is overexpressed in PIA and increases in chronic prostatic inflammation. ${ }^{16}$ Glutathione S-transferase P1 inactivation, mostly by hypermethylation, is associated with high-grade PIN and $\mathrm{CaP}$ and may increase prostate cells' susceptibility to additional genomic damage induced by inflammatory oxidant or nutritional carcinogens, with consequent selective growth and proliferation. ${ }^{16}$

\section{Role of hormones in CaP}

A growing body of evidence supporting the important role of estrogens in human $\mathrm{CaP}$ is accumulating, although mechanisms underlying the implication of estrogens in prostate carcinogenesis remain totally unspecified. Both in vitro studies and in vivo animal models have suggested that androgens and estrogens play an important role in the development and/or progression of cancer. ${ }^{104}$ For instance, long-term administration of testosterone and estradiol induce a high-incidence risk of rat prostate adenocarcinoma. High levels of estrogen in the presence of testosterone induce an early (4 weeks) prostate-specific inflammatory response and a later development of prostate carcinomas (nearly 50 weeks) in Noble rats, suggesting that estrogen-induced early inflammatory events are a prerequisite for the onset of $\mathrm{CaP}^{16,105}$ Additionally, chronic exposure of Wistar rats to estradiol and dihydrotestosterone results in an early upregulation of IL-1 $\beta$, IL-6, and inducible nitric oxide synthase, later accompanied by an increase in IL- 4 and IL- 5 expression that occurred irrespective of the presence of inflammatory cells and resembled a type- 2 helper response. ${ }^{106}$ Lastly, estrogens neonatally administered to rodents induce an imprinted state called developmental estrogenization, resulting in the development of lobe-specific inflammation, hyperplasia, and/or PIN and dysplasia. ${ }^{107}$

\section{Chronic inflammation as a possible link between BPH and CaP}

A growing body of evidence suggests that chronic inflammation is a common condition in the human prostate and it could be initiated by several known or unknown stimuli that would determine the proinflammatory status in the prostatic microenvironment. The inflammatory infiltrates mostly composed by leukocytes are responsible for the secretion of cytokines involved in the paracrine and autocrine regulation of prostatic stromal and epithelial cell growth. As in the context of chronic inflammation and proinflammatory cytokine expression, the activity of IL-6, IL-8, IL-15, and IL-17 has been considered influential in the development of both diseases (BPH and $\mathrm{CaP}$ ) (Table 1), although further confirmatory studies are needed.

So far, it can be hypothesized that chronic prostatic inflammation could be considered one of the possible conditions associated with $\mathrm{BPH}, \mathrm{CaP}$, or both. Further research on inflammatory responses within the prostate is needed to improve knowledge on the mechanisms involved in the interaction among inflammatory infiltrates, prostatic stroma, and prostatic epithelium. More clarification is also needed to elucidate whether or not chronic prostatic inflammation could be considered the starting point for the development of benign and malignant proliferative disease of the prostate. With this in mind, there is a need to improve the capability to define the type of, and quantify, asymptomatic prostatic inflammation. Research into the relationship among BPH, $\mathrm{CaP}$, and chronic prostatic inflammation may benefit from improving clinical imaging for the diagnosis of individual conditions and from a better histologic characterization of the spatial distribution of inflammatory infiltrates, BPH nodules, and preneoplastic and neoplastic lesions of the prostate. 
Table I Inflammatory mediators involved in benign prostatic hyperplasia and prostate cancer pathogenesis

\begin{tabular}{|c|c|c|}
\hline Cytokine & Expression pattern & Function \\
\hline IL-2 & Produced by BPH T-cells, epithelial, and stromal cells & Stimulation of prostatic stromal cell growth \\
\hline \multirow[t]{2}{*}{ IL-6 } & Produced by BPH epithelial and stromal cells & Paracrine and autocrine epithelial cell growth regulatory loop \\
\hline & Produced by $\mathrm{CaP}$ human cells & Promotes the malignant process; induces apoptosis and angiogenesis \\
\hline \multirow[t]{2}{*}{ IL-8 } & Produced by BPH epithelial and stromal cells & $\begin{array}{l}\text { Potent growth factor for prostatic stromal and epithelial cells; } \\
\text { recruitment of inflammatory cells }\end{array}$ \\
\hline & Produced by CaP human cells & Promotes tumor cell growth \\
\hline IL-I5 & Produced by BPH stromal cells & Increase in proliferative rate (growth and survival of prostatic cells) \\
\hline \multirow[t]{2}{*}{ IL-I7 } & Produced by activated BPH T-cells & $\begin{array}{l}\text { Strong induction of IL- } 6 \text { and IL- } 8 \text { production by prostate epithelial } \\
\text { and stromal cells }\end{array}$ \\
\hline & $\begin{array}{l}\text { Produced by CD4 T-cells; expressed by human } \\
\text { malignant prostate tissues }\end{array}$ & $\begin{array}{l}\text { Induction of angiogenesis and in vivo growth of tumor cells; } \\
\text { promotes prostate tumor cells growth and metastasis }\end{array}$ \\
\hline Interferon- $\gamma$ & $\begin{array}{l}\text { Produced by BPH T-cells, epithelial, stromal, } \\
\text { and endothelial cells }\end{array}$ & $\begin{array}{l}\text { Induction of proliferation of BPH stromal cell lines; stimulation of } \\
\text { the growth of BPH epithelial cells }\end{array}$ \\
\hline \multirow[t]{2}{*}{ Tumor growth factor- $\beta$} & Produced by BPH stromal cells & Support the fibromuscular growth in $\mathrm{BPH}$ \\
\hline & Expressed by serum of human $\mathrm{CaP}$ patients & Increase tumor cell survival and predict poor CaP prognosis \\
\hline Tumor necrosis factor- $\alpha$ & Expressed malignant prostate tissues & $\begin{array}{l}\text { Increase expression of MMP-9 involved in tumor progression and } \\
\text { metastasis in vitro and in vivo }\end{array}$ \\
\hline Fibroblast growth factor-2 & Produced by BPH T-cells & Growth factor for prostatic stromal and epithelial cells \\
\hline
\end{tabular}

Abbreviations: BPH, benign prostatic hyperplasia; CaP, prostatic cancer; CD4, cluster of differentiation-4; IL, interleukin; MMP-9, matrix metalloproteinase-9.

\section{Conclusion}

While the pathogenesis of both diseases, $\mathrm{BPH}$ and $\mathrm{CaP}$, is not fully understood and several mechanisms seem to be involved in their initiation and progression, a growing body of evidence suggests the important role of inflammatory infiltrates and their mediators in the development of chronic prostatic diseases. Chronic prostatic inflammation, a common condition in human prostates, should not be considered only as an occasional histologic finding in prostate specimens but as a possible link between $\mathrm{BPH}$ and CaP. It may result from the immunologic response of different pathogens that induce prostatic tissue damage and subsequent chronic processes of repetitive wound healing, and it may have a role in $\mathrm{BPH}$ growth and its progression toward dysplasia and cancer. Further basic and clinical research in the area and trying to understand the etiology of prostatic inflammation and its pathway may help to identify new therapeutic targets and novel strategies for reducing the risk of developing benign and malignant tumors of the prostate.

\section{Disclosure}

The author reports no conflicts of interest in this work.

\section{References}

1. De Marzo AM, Coffey DS, Nelson WG. New concepts in tissue specificity for prostate cancer and benign prostatic hyperplasia. Urology. 1999;53(3 Suppl 3a):29-39.

2. McVary KT. BPH: epidemiology and comorbidities. Am J Manag Care. 2006;12(Supp1 5):S122-S128.

3. Fitzpatrick JM. The natural history of benign prostatic hyperplasia. $B J U$ Int. 2006;97(Suppl 2):3-6.
4. Fitzpatrick JM, Kirby RS. Management of acute urinary retention. BJU Int. 2006;97(Suppl 2):16-20.

5. Roehrborn CG. Pathology of benign prostatic hyperplasia. Int J Impot Res. 2008;20(Suppl 3):S11-S18.

6. Siegel R, Naishadham D, Jemal A. Cancer statistics, 2012. CA Cancer J Clin. 2012;62(1):10-29.

7. Alcaraz A, Hammerer P, Tubaro A, Scroder FH, Castro R. Is there evidence of a relationship between benign prostatic hyperplasia and prostate cancer? Findings of a literature review. Eur Urol. 2009;55(4): 864-873.

8. McNeal JE. Normal histology of the prostate. Am J Surg Pathol. 1988; 12(8):619-633.

9. McNeal JE. Normal anatomy of the prostate and changes in benign prostatic hypertrophy and carcinoma. Semin Ultrasound CT MR. 1988;9(5):329-334.

10. McNeal JE, Redwine EA, Freiha FS, Stamey TA. Zonal distribution of prostatic adenocarcinoma. Correlation with histologic pattern and direction of spread. Am J Surg Pathol. 1988;12(12):897-906.

11. Sfanos KS, De Marzo AM. Prostate cancer and inflammation: the evidence. Histopathology. 2012;60(1):199-215.

12. Chughtai B, Lee R, Te A, Kaplan S. Role of inflammation in benign prostatic hyperplasia. Rev Urol. 2011;13(3):147-150.

13. Wagenlehner FM, Elkahwaji JE, Algaba F, et al. The role of inflammation and infection in the pathogenesis of prostate carcinoma. BJU Int. 2007;100(4):733-737.

14. Omabe M, Ezeani M. Infection, inflammation and prostate carcinogenesis. Infect Genet Evol. 2011;11(6):1195-1198.

15. De Marzo AM, Nakai Y, Nelson WG. Inflammation, atrophy, and prostate carcinogenesis. Urol Oncol. 2007;25(5):398-400.

16. De Marzo AM, Platz EA, Sutcliffe S, et al. Inflammation in prostate carcinogenesis. Nat Rev Cancer. 2007;7(4):256-269.

17. Ames BN, Gold LS, Willett WC. The causes and prevention of cancer. Proc Natl Acad Sci U S A. 1995;92(12):5258-5265.

18. Giovannucci E. Medical history and etiology of prostate cancer. Epidemiol Rev. 2001;23(1):159-162.

19. Albini A, Sporn MB. The tumour microenvironment as a target for chemoprevention. Nat Rev Cancer. 2007;7(2):139-147.

20. Robert G, Salagierski M, Schalken JA, de la Taille A. Inflammation and benign prostatic hyperplasia: cause or consequence? Prog Urol. 2010;20(6):402-407. French. 
21. Schatteman PH, Hoekx L, Wyndaele JJ, Jeuris W, Van Marck E. Inflammation in prostate biopsies of men without prostatic malignancy or clinical prostatitis: correlation with total serum PSA and PSA density. Eur Urol. 2000;37(4):404-412.

22. Fibbi B, Penna G, Morelli A, Adorini L, Maggi M. Chronic inflammation in the pathogenesis of benign prostatic hyperplasia. Int $J$ Androl. 2010;33(3):475-488.

23. Nickel JC, Roehrborn CG, O'Leary MP, Bostwick DG, Somerville MC, Rittmaster RS. Examination of the relationship between symptoms of prostatitis and histological inflammation: baseline data from the REDUCE chemoprevention trial. J Urol. 2007;178(3 Pt 1): 896-900.

24. Nickel JC, Roehrborn CG, O'Leary MP, Bostwick DG, Somerville MC, Rittmaster RS. The relationship between prostate inflammation and lower urinary tract symptoms: examination of baseline data from the REDUCE trial. Eur Urol. 2008;54(6):1379-1384.

25. Robert G, Descazeaud A, Nicolaiew N, et al. Inflammation in benign prostatic hyperplasia: a 282 patients' immunohistochemical analysis. Prostate. 2009;69(16):1774-1780.

26. De Marzo AM, Marchi VL, Epstein JI, Nelson WG. Proliferative inflammatory atrophy of the prostate: implications for prostatic carcinogenesis. Am J Pathol. 1999;155(6):1985-1992.

27. Nelson WG, De Marzo AM, DeWeese TL, Isaacs WB. The role of inflammation in the pathogenesis of prostate cancer. $J$ Urol. 2004 172(5 Pt 2):S6-S11.

28. Palapattu GS, Sutcliffe S, Bastian PJ, et al. Prostate carcinogenesis and inflammation: emerging insights. Carcinogenesis. 2005;26(7): $1170-1181$.

29. De Marzo AM, Meeker AK, Zha S, et al. Human prostate cancer precursors and pathobiology. Urology. 2003;62(5 Suppl 1):55-62.

30. Nelson WG, De Marzo AM, Isaacs WB. Prostate cancer. $N$ Engl J Med. 2003;349(4):366-381.

31. De Marzo AM, Nelson WG, Isaacs WB, Epstein JI. Pathological and molecular aspects of prostate cancer. Lancet. 2003;361(9361) 955-964.

32. Klein EA, Silverman R. Inflammation, infection, and prostate cancer. Curr Opin Urol. 2008;18(3):315-319.

33. Sutcliffe S. Sexually transmitted infections and risk of prostate cancer: review of historical and emerging hypotheses. Future Oncol. 2010;6(8): 1289-1311.

34. Pelouze PS. Gonorrhea in the Male and Female: A Book for Practitioners. Philadelphia, PA: WB Saunders; 1935.

35. Handsfield HH, Lipman TO, Harnisch JP, Tronca E, Holmes KK Asymptomatic gonorrhea in men. Diagnosis, natural course, prevalence and significance. N Engl J Med. 1974;290(3):117-123.

36. Poletti F, Medici MC, Alinovi A, et al. Isolation of Chlamydia trachomatis from the prostatic cells in patients affected by nonacute abacterial prostatitis. J Urol. 1985;134(4):691-693.

37. Gardner WA Jr, Culberson DE, Bennett BD. Trichomonas vaginalis in the prostate gland. Arch Pathol Lab Med. 1986;110(5):430-432.

38. Thomson L. Syphilis of the prostate. Am J Syphilis. 1920;4:323-341.

39. Bushman W. Etiology of Prostatitis In: Lepor H, editor. Prostatic Diseases. Philadelphia, PA: WB Saunders; 2000:550-557.

40. Strickler HD, Goedert JJ. Sexual behavior and evidence for an infectious cause of prostate cancer. Epidemiol Rev. 2001;23(1):144-151.

41. Zambrano A, Kalantari M, Simoneau A, Jensen JL, Villarreal LP. Detection of human polyomaviruses and papillomaviruses in prostatic tissue reveals the prostate as a habitat for multiple viral infections. Prostate. 2002;53(4):263-276.

42. Samanta M, Harkins L, Klemm K, Britt WJ, Cobbs CS. High prevalence of human cytomegalovirus in prostatic intraepithelial neoplasia and prostatic carcinoma. J Urol. 2003;170(3):998-1002.

43. Kirby RS, Lowe D, Bultitude MI, Shuttleworth KE. Intra-prostatic urinary reflux: an aetiological factor in abacterial prostatitis. Br J Urol. 1982;54(6):729-731.

44. Isaacs JT. Prostatic structure and function in relation to the etiology of prostatic cancer. Prostate. 1983;4(4):351-366.
45. Martinon F, Petrilli V, Mayor A, Tardivel A, Tschopp J. Gout-associated uric acid crystals activate the NALP3 inflammasome. Nature. 2006; 440(7081):237-241.

46. Drachenberg CB, Papadimitriou JC. Prostatic corpora amylacea and crystalloids: similarities and differences on ultrastructural and histochemical studies. J Submicrosc Cytol Pathol. 1996;28(2):141-150.

47. Sugimura T, Wakabayashi K, Nakagama H, Nagao M. Heterocyclic amines: mutagens/carcinogens produced during cooking of meat and fish. Cancer Sci. 2004;95(4):290-299.

48. Knize MG, Felton JS. Formation and human risk of carcinogenic heterocyclic amines formed from natural precursors in meat. Nutr Rev. 2005;63(5):158-165.

49. Borowsky AD, Dingley KH, Ubick E, Turteltaub KW, Cardiff RD, Devere-White R. Inflammation and atrophy precede prostatic neoplasia in a PhIP-induced rat model. Neoplasia. 2006;8(9):708-715.

50. Coffey DS. Similarities of prostate and breast cancer: evolution, diet, and estrogens. Urology. 2001;57(4 Suppl 1):31-38.

51. Harkonen PL, Makela SI. Role of estrogens in development of prostate cancer. J Steroid Biochem Mol Biol. 2004;92(4):297-305.

52. Gilleran JP, Putz O, DeJong M, et al. The role of prolactin in the prostatic inflammatory response to neonatal estrogen. Endocrinology. 2003;144(5):2046-2054.

53. Huang L, Pu Y, Alam S, Birch L, Prins GS. Estrogenic regulation of signaling pathways and homeobox genes during rat prostate development. J Androl. 2004;25(3):330-337.

54. Naslund MJ, Strandberg JD, Coffey DS. The role of androgens and estrogens in the pathogenesis of experimental nonbacterial prostatitis. J Urol. 1988;140(5):1049-1053.

55. Huang L, Pu Y, Alam S, Birch L, Prins GS. The role of Fgf10 signaling in branching morphogenesis and gene expression of the rat prostate gland: lobe-specific suppression by neonatal estrogens. Dev Biol. 2005; 278(2):396-414

56. Prins GS, Birch L, Couse JF, Choi I, Katzenellenbogen B, Korach KS. Estrogen imprinting of the developing prostate gland is mediated through stromal estrogen receptor $\alpha$ : studies with $\alpha E R K O$ and $\beta E R K O$ mice. Cancer Res. 2001;61(16):6089-6097.

57. Ponniah S, Arah I, Alexander RB. PSA is a candidate self-antigen in autoimmune chronic prostatitis/chronic pelvic pain syndrome. Prostate. 2000;44(1):49-54.

58. Briganti A, Capitanio U, Suardi N, et al. Benign prostatic hyperplasia and its aetiologies. Eur Urol Suppl. 2009;8(13):865-871.

59. Abdollah F, Briganti A, Suardi N, et al. Metabolic syndrome and benign prostatic hyperplasia: evidence of a potential relationship, hypothesized etiology, and prevention. Korean J Urol. 2011;52(8):507-516.

60. Robert G, Descazeaud A, Allory Y, Vacherot F, de la Taille A. Should we investigate prostatic inflammation for the management of benign prostatic hyperplasia? Eur Urol Suppl. 2009;8(13):879-886.

61. Kramer G, Mitteregger D, Marberger M. Is benign prostatic hyperplasia (BPH) an inflammatory disease? Eur Urol. 2007;51(5):1202-1216.

62. Jahnisch H, Fussel S, Kiessling A, et al. Dendritic cell-based immunotherapy for prostate cancer. Clin Dev Immunol. 2010;2010:517493.

63. Kramer G, Marberger M. Could inflammation be a key component in the progression of benign prostatic hyperplasia? Curr Opin Urol. 2006;16(1):25-29.

64. Steiner GE, Newman ME, Paikl D, et al. Expression and function of proinflammatory interleukin IL-17 and IL-17 receptor in normal, benign hyperplastic, and malignant prostate. Prostate. 2003;56(3):171-182.

65. Steiner GE, Stix U, Handisurya A, et al. Cytokine expression pattern in benign prostatic hyperplasia infiltrating $\mathrm{T}$ cells and impact of lymphocytic infiltration on cytokine mRNA profile in prostatic tissue. Lab Invest. 2003;83(8):1131-1146.

66. Caruso C, Balistreri CR, Candore G, et al. Polymorphisms of proinflammatory genes and prostate cancer risk: a pharmacogenomic approach. Cancer Immunol Immunother. 2009;58(12):1919-1933.

67. Wang L, Yang JR, Yang JY, Liu ZT. Chronic inflammation in benign prostatic hyperplasia: implications for therapy. Med Hypotheses. 2008;70(5):1021-1023. 
68. Penna G, Fibbi B, Amuchastegui S, et al. Human benign prostatic hyperplasia stromal cells as inducers and targets of chronic immunemediated inflammation. J Immunol. 2009;182(7):4056-4064.

69. Descazeaud A, Weinbreck N, Robert G, et al. Transforming growth factor $\beta$-receptor II protein expression in benign prostatic hyperplasia is associated with prostate volume and inflammation. BJU Int. 2011; 108(2 Pt 2):E23-E28.

70. Sutcliffe S. Sexually transmitted infections and risk of prostate cancer: review of historical and emerging hypotheses. Future Oncol. 2010;6(8): 1289-1311.

71. Sutcliffe S, Platz EA. Inflammation and prostate cancer: a focus on infections. Curr Urol Rep. 2008;9(3):243-249.

72. Vasto S, Carruba G, Candore G, Italiano E, Di Bona D, Caruso C. Inflammation and prostate cancer. Future Oncol. 2008;4(5):637-645.

73. Dennis LK, Lynch CF, Torner JC. Epidemiologic association between prostatitis and prostate cancer. Urology. 2002;60(1):78-83.

74. Roberts RO, Bergstralh EJ, Bass SE, Lieber MM, Jacobsen SJ. Prostatitis as a risk factor for prostate cancer. Epidemiology. 2004;15(1):93-99.

75. Cohen RJ, Shannon BA, McNeal JE, Shannon T, Garrett KL. Propionibacterium acnes associated with inflammation in radical prostatectomy specimens: a possible link to cancer evolution? J Urol. 2005;173(6):1969-1974.

76. Hayes RB, Pottern LM, Strickler H, et al. Sexual behaviour, STDs and risks for prostate cancer. Br J Cancer. 2000;82(3):718-725.

77. Strickler HD, Goedert J. Sexual behavior and evidence for an infectious cause of prostate cancer. Epidemiol Rev. 2001;23(1):144-151.

78. Dennis LK, Dawson DV. Meta-analysis of measures of sexual activity and prostate cancer. Epidemiology. 2002;13(1):72-79.

79. Taylor ML, Mainous AG 3rd, Wells BJ. Prostate cancer and sexually transmitted diseases: a meta-analysis. Fam Med. 2005;37(7):506-512.

80. Rosenblatt KA, Wicklund KG, Stanford JL. Sexual factors and the risk of prostate cancer. Am J Epidemiol. 2001;153(12):1152-1158.

81. Hochreiter WW, Nadler RB, Koch AE, et al. Evaluation of the cytokines interleukin 8 and epithelial neutrophil activating peptide 78 as indicators of inflammation in prostatic secretions. Urology. 2000;56(6): 1025-1029.

82. Fujita K, Ewing CM, Sokoll LJ, et al. Cytokine profiling of prostatic fluid from cancerous prostate glands identifies cytokines associated with extent of tumor and inflammation. Prostate. 2008;68(8):872-882.

83. Voronov E, Shouval DS, Krelin Y, et al. IL-1 is required for tumor invasiveness and angiogenesis. Proc Natl Acad Sci USA. 2003;100(5): 2645-2650

84. Culig Z, Puhr M. Interleukin-6: a multifunctional targetable cytokine in human prostate cancer. Mol Cell Endocrinol. 2012;360(1-2):52-58.

85. Malinowska K, Neuwirt H, Cavarretta IT, et al. Interleukin-6 stimulation of growth of prostate cancer in vitro and in vivo through activation of the androgen receptor. Endocr Relat Cancer. 2009;16(1):155-169.

86. Culig Z, Steiner H, Bartsch G, Hobisch A. Interleukin-6 regulation of prostate cancer cell growth. J Cell Biochem. 2005;95(3):497-505.

87. Michalaki V, Syrigos K, Charles P, Waxman J. Serum levels of IL-6 and TNF- $\alpha$ correlate with clinicopathological features and patient survival in patients with prostate cancer. Br J Cancer. 2004;90(12):2312-2316.

88. Numasaki M, Fukushi J, Ono M, et al. Interleukin-17 promotes angiogenesis and tumor growth. Blood. 2003;101(7):2620-2627.

89. Inoue K, Slaton JW, Eve BY, et al. Interleukin 8 expression regulates tumorigenicity and metastases in androgen-independent prostate cancer. Clin Cancer Res. 2000;6(5):2104-2119.

Research and Reports in Urology

\section{Publish your work in this journal}

Research and Reports in Urology is an international, peer-reviewed, open access journal publishing original research, reports, editorials, reviews and commentaries on all aspects of adult and pediatric urology in the clinic and laboratory including the following topics: Pathology, pathophysiology of urological disease; Investigation and treatment of
90. Uehara H, Troncoso P, Johnston D, et al. Expression of interleukin-8 gene in radical prostatectomy specimens is associated with advanced pathologic stage. Prostate. 2005;64(1):40-49.

91. Scott KA, Arnott $\mathrm{CH}$, Robinson SC, et al. TNF- $\alpha$ regulates epithelial expression of MMP-9 and integrin $\alpha v \beta 6$ during tumour promotion. A role for TNF- $\alpha$ in keratinocyte migration? Oncogene. 2004;23(41): 6954-6966.

92. Thomas GJ, Lewis MP, Hart IR, Marshall JF, Speight PM. $\alpha v \beta 6$ integrin promotes invasion of squamous carcinoma cells through up-regulation of matrix metalloproteinase-9. Int J Cancer. 2001;92(5): 641-650.

93. Park JI, Lee MG, Cho K, et al. Transforming growth factor- $\beta 1$ activates interleukin-6 expression in prostate cancer cells through the

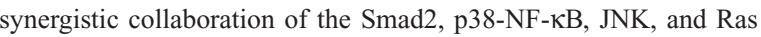
signaling pathways. Oncogene. 2003;22(28):4314-4332.

94. Lu T, Burdelya LG, Swiatkowski SM, et al. Secreted transforming growth factor $\beta 2$ activates NF- $\kappa \mathrm{B}$, blocks apoptosis, and is essential for the survival of some tumor cells. Proc Natl Acad Sci U S A. 2004; 101(18):7112-7117.

95. Lu S, Dong Z. Characterization of TGF- $\beta$-regulated interleukin-8 expression in human prostate cancer cells. Prostate. 2006;66(9): 996-1004

96. Lu Y, Cai Z, Xiao G, Liu Y, et al. CCR2 expression correlates with prostate cancer progression. J Cell Biochem. 2007;101(3):676-685.

97. Vaday GG, Peehl DM, Kadam PA, Lawrence DM. Expression of CCL5 (RANTES) and CCR5 in prostate cancer. Prostate. 2006;66(2): 124-134.

98. Konig JE, Senge T, Allhoff EP, Konig W. Analysis of the inflammatory network in benign prostate hyperplasia and prostate cancer. Prostate. 2004;58(2):121-129.

99. Hussain T, Gupta S, Mukhtar H. Cyclooxygenase-2 and prostate carcinogenesis. Cancer Lett. 2003;191(2):125-135.

100. Fujita H, Koshida K, Keller ET, et al. Cyclooxygenase-2 promotes prostate cancer progression. Prostate. 2002;53(3):232-240.

101. Edwards J, Mukherjee R, Munro AF, Wells AC, Almushatat A, Bartlett JM. Her2 and COX2 expression in human prostate cancer. Eur J Cancer. 2004;40(1):50-55.

102. Aparicio Gallego G, Diaz Prado S, Jimenez Fonseca P, Garcia Campelo R, Cassinello Espinosa J, Anton Aparicio LM. Cyclooxygenase-2 (COX-2): a molecular target in prostate cancer. Clin Transl Oncol. 2007;9(11):694-702.

103. Wang W, Bergh A, Damber JE. Chronic inflammation in benign prostate hyperplasia is associated with focal upregulation of cyclooxygenase-2, Bcl-2, and cell proliferation in the glandular epithelium. Prostate. 2004;61(1):60-72.

104. Risbridger GP, Bianco JJ, Ellem SJ, McPherson SJ. Oestrogens and prostate cancer. Endocr Relat Cancer. 2003;10(2):187-191.

105. Tam NN, Leav I, Ho SM. Sex hormones induce direct epithelial and inflammation-mediated oxidative/nitrosative stress that favors prostatic carcinogenesis in the noble rat. Am J Pathol. 2007;171(4): 1334-1341.

106. Harris MT, Feldberg RS, Lau KM, Lazarus NH, Cochrane DE. Expression of proinflammatory genes during estrogen-induced inflammation of the rat prostate. Prostate. 2000;44(1):19-25.

107. Prins GS, Huang L, Birch L, Pu Y. The role of estrogens in normal and abnormal development of the prostate gland. Ann N Y Acad Sci. 2006;1089:1-13.

\section{Dovepress}

urological disease; Pharmacology of drugs used for the treatment of urological disease. The manuscript management system is completely online and includes a very quick and fair peer-review system, which is all easy to use. Visit http://www.dovepress.com/testimonials.php to read real quotes from published authors. 